\title{
Vertical Distribution of Typical Petroleum Pollutants in an Oilfield of Gudao, china
}

\author{
Xiaohua Ren ${ }^{a}$, Shanshan Zhang ${ }^{b}$ \\ Weifang University of Science and Technology, Shouguang 262700, China. \\ arenxiaohua2008@163.com, 'bhangshanshan1819@163.com
}

Keywords: oil pollution, total petroleum hydrocarbons, PAHs, vertical distribution.

\begin{abstract}
In oilfields, crude oil exploiting process led to heavy soil contamination with petroleum pollutants. In this work, ten soil profile samples were collected and analyzed with GC-MS method to investigate the vertical distribution of typical petroleum pollutants in an oilfield of Gudao Region. The results showed that the highest concentrations of the five typical petroleum pollutants appeared in the range of $0-40 \mathrm{~cm}$ depth, and then the concentrations of these pollutants gradually decreased with increasing soil depth below $40 \mathrm{~cm}$. The peak concentrations of total petroleum hydrocarbons (TPHs), polycyclic aromatic hydrocarbons (PAHs) and sulfur were $33.84 \mathrm{~g} / \mathrm{kg}, 4624.58 \mu \mathrm{g} / \mathrm{kg}$ and $1298.50 \mathrm{mg} / \mathrm{kg}$, respectively, all found in the $0-10 \mathrm{~cm}$ soil layer of the profile. The $\mathrm{n}$-alkanes content of $88.10 \mathrm{mg} / \mathrm{kg}$ was highest at the $10-20 \mathrm{~cm}$ depth of the soil profile. The highest content of 3293.68 $\mu \mathrm{g} / \mathrm{kg}$ for BETX (Benzene, Toluene, Ethylbenzene and Xylenes) appeared at the 30-40 cm soil layer. The soil size and organic matter content were the probable factors affecting the vertical distribution of the pollutants. The results could provide basic data for pollution monitoring and soil remediation.
\end{abstract}

\section{Introduction}

Economic development caused a significant enhancement of crude oil extraction and utilization. Similar to various other mining activities, the crude oil exploration process inevitably induced serious environmental pollution. As an example, total petroleum hydrocarbons (TPHs) and polycyclic aromatic hydrocarbons (PAHs), being important petroleum pollutants, have drawn the attention of the related researchers due to their mutagenic and carcinogenic potential $[1,2]$. However, in the Yellow River Delta, most studies focused on the distributions of heavy metals, N and P [3, 4]; A few studies on the distributions of hydrocarbon pollutants [5-7] have been undertaken, but rarely on aliphatic hydrocarbons such as TPHs, PAHs and n-alkanes in the oilfield [8], which have great significance to pollution control and soil remediation.

The paper aims to elucidate the vertical distribution characteristics of the typical petroleum pollutants in the oilfield soil through analyzing the concentrations in different soil profile layers, and to find out the possible reasons affecting the distributions of these pollutants.

\section{Materials and Methods}

\subsection{Study Area.}

The study area was located in Gudao Region of Shengli Oilfield (the second biggest oilfield in China), north of the Yellow River Delta (Fig. 1). Gudao town is a new developing oil-industry town based on oil exploitation, which has a long oil exploitation history of more than 40 years and a short urbanization history of about 20 years. The average annual temperature of the study area is $12.1{ }^{\circ} \mathrm{C}$, and the annual precipitation is approximate $580 \mathrm{~mm}$. The soils in the study area are mostly fluvo-aquic and coastal solonchaks (World Reference Base for Soil Resources). 


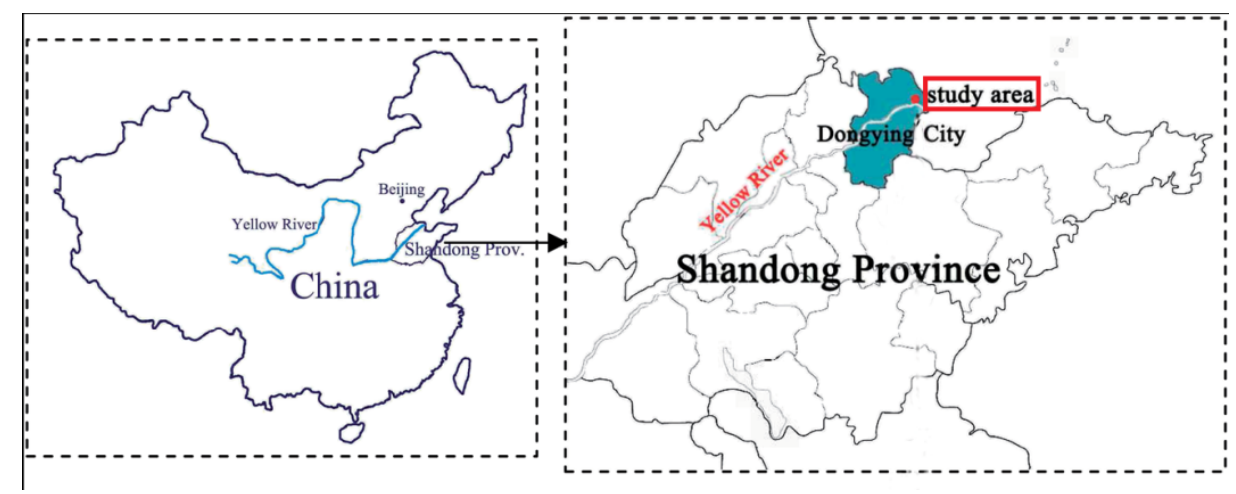

Fig.1 Location of the study area

\subsection{Sampling Procedure.}

Ten profile soil samples were collected in July, 2013 near oil wells where the soils were contaminated by crude oil to investigate the vertical distribution of typical petroleum pollutants. A pit was dug with dimensions of $1.5 \mathrm{~m}$ length, $0.8 \mathrm{~m}$ width and $1.0 \mathrm{~m}$ depth, and then the soil samples were collected with $10 \mathrm{~cm}$ intervals from bottom to surface. For each sample, firstly, at least three subsamples of similar weights with about $1 \mathrm{~kg}$ were collected with a plastic scoop and a stainless steel shovel. Secondly, the subsamples were mixed together homogeneously. Finally, the weight of the mixed sample was decreased to be about $1 \mathrm{~kg}$ with the quarter method to improve the sample representativeness [9]. The soil samples were stored in plastic bags.

\subsection{Sample Analysis.}

The soil samples were dried at room temperature and then purified by discarding the plant roots and stones. The soil sample (15 g, dry weight) were Soxhlet extracted using $300 \mathrm{ml}$ dichloromethane for $24 \mathrm{~h}$. Activated copper and zeolite were added to remove the elemental sulfur. After extraction, the extract was concentrated to a volume of about 2-3 $\mathrm{ml}$. Then, the extract was evaporated and weighed, and n-hexane was added to the extract to precipitate the asphaltene. Finally, the extract was evaporated and weighed again. The total petroleum hydrocarbons (TPHs) content was the difference between the two weights. The extract was solvent-exchanged into $20 \mathrm{ml}$-hexane to reduce the volume to about $1-2 \mathrm{ml}$ with a rotary vacuum evaporator. PAHs and $\mathrm{n}$-alkanes were fractionated by $40 \mathrm{ml}$ dichloromethane/n-hexane (v/v 1/1) and $25 \mathrm{ml}$-hexane using a 2:1 silica gel/alumina column, respectively. The PAHs fraction and n-alkanes fraction were then condensed to $1 \mathrm{ml}$ by rotary vacuum evaporator and finally to $0.2 \mathrm{ml}$ under a gentle gas stream of high purity nitrogen, respectively.

The PAHs were analyzed by gas chromatography coupled to mass spectrometry (GC-MS) (Agilent/6890N-5973N, Agilent Co., USA) with helium as carry gas. The n-alkanes were analyzed with gas chromatography (GC-2014, Shimadzu Co., Japan). The BTEX components were determined with a purge-and-trap sample concentrator (Eclipse 4660, OI analysis instrument Co., USA ) in combination with gas chromatography. The sulfur was determined using high frequency IR carbon-sulfur spectrometer (CS-878A, Sichuan JingKe Instrument Manufac turing Co., Ltd., China).

\subsection{Quality Assurance and Quality Control (QA/QC).}

Method blanks (solvent) and spiked blanks (standards spiked into solvent) were applied as quality assurance and quality control methods. The relative standard deviations and recoveries of PAHs, n-alkanes and BTEX ranged from 1.8-12.5\% and 75.8-98.5\%, 2.5-14.1\% and 76.5-102.3\%, and 4.6-14.3\% and $83.2-99.7 \%$, respectively. The detection limits of PAHs, n-alkanes and BTEX were in range of $2.3-23.7,3.2-19.5$ and $0.132-0.679 \mu \mathrm{g} / \mathrm{kg}$, respectively. Additionally, the relative standard deviation and detection limit for sulfur was $4.9 \%$ and $0.013 \mathrm{~g} / \mathrm{kg}$, respectively.

\section{Results and Discussion}

Five typical petroleum pollutants, total petroleum hydrocarbons (TPHs), polycyclic aromatic hydrocarbons (PAHs), n-alkanes, BTEX (Benzene, Toluene, Ethylbenzene and Xylenes) and sulfur, 
were chosen as the representatives to investigate the vertical distribution for their toxicity, persistence and representativeness in the study.

Fig. 2 illustrated the vertical concentration distribution of petroleum pollutants along the soil profile of the oilfield.

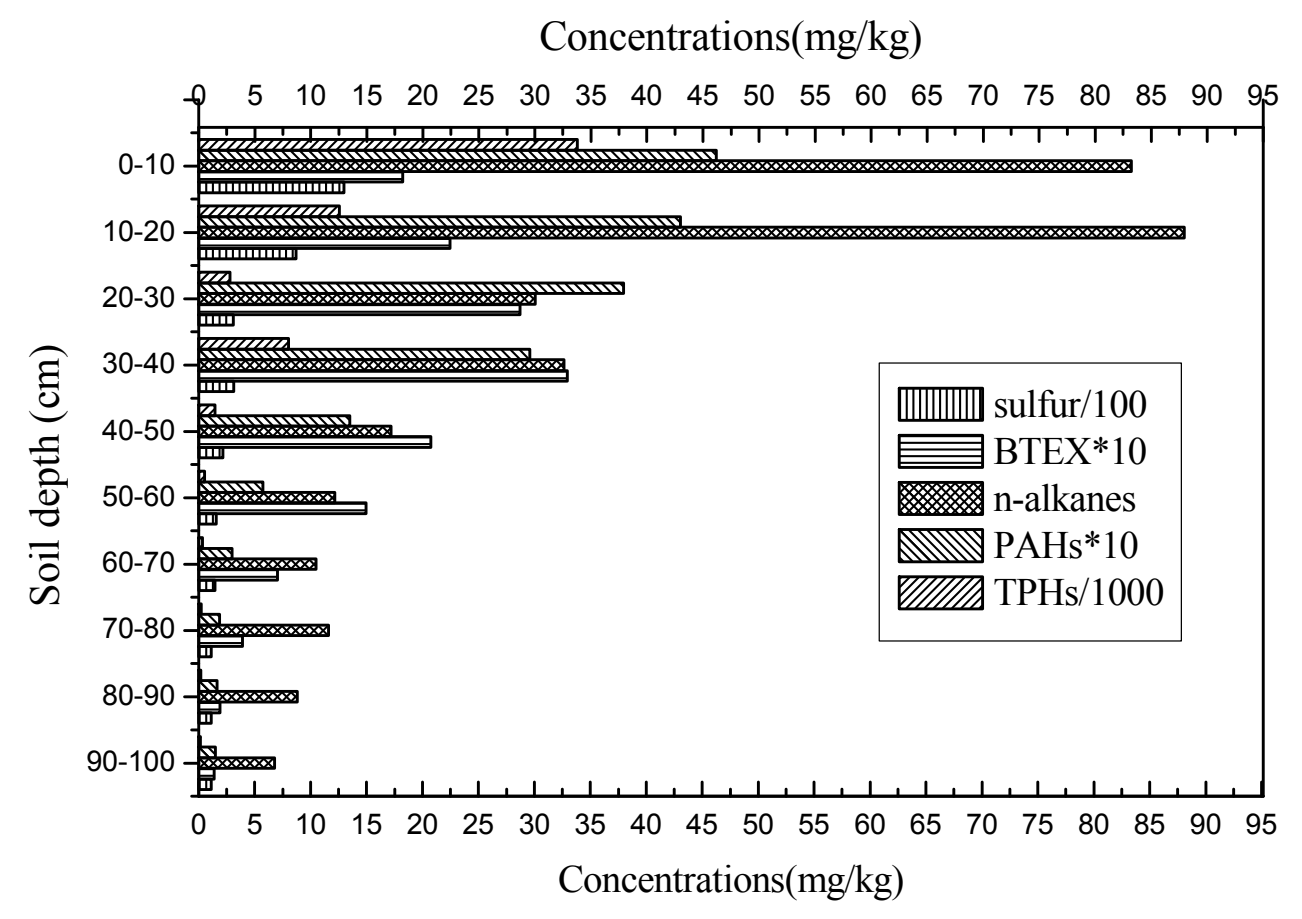

Fig. 2 Vertical distribution of petroleum pollutants in the oil-polluted soil profile

As seen in Fig. 2, from the top to the bottom of the profile, the highest concentrations of the five typical petroleum pollutants appeared in the range of 0-40 cm, and then the concentrations of these pollutants generally decreased with the increase depth below $40 \mathrm{~cm}$.

For TPHs, the concentrations in the soil from the surface to the depth of $60 \mathrm{~cm}$ were all above the national pollutant control standard $(500 \mathrm{mg} / \mathrm{kg})$ [10], suggesting that these layers were all polluted by petroleum. First, the TPHs contents were reduced significantly from $33.84 \mathrm{~g} / \mathrm{kg}$ to $2.80 \mathrm{~g} / \mathrm{kg}$ from the surface to the 20-30 cm depth. Second, the TPHs content was slightly increased to $8.02 \mathrm{~g} / \mathrm{kg}$ at the depth of 30-40 cm. Finally, the concentrations of TPHs were decreased gradually from the $30-40 \mathrm{~cm}$ depth to the bottom of $90-100 \mathrm{~cm}$. The possible reasons were as follows: the upper soil is mostly sandy, which has strong permeability, weak retention, multi-porosity and low organic carbon content, leading to increasing the infiltration rate and depth of TPHs in the soil profile; On the other hand, the thick property of the oil in Gudao Region results in that the TPHs concentration in the upper layer is several times higher than in the lower layer; The small peak at the depth of $30-40 \mathrm{~cm}$ is probably ascribed to the accumulation of petroleum pollutants for many years; Below $60 \mathrm{~cm}$ depth, it is difficult for TPHs to migrate to next layer because of the weak permeability and strong retention of the clay.

As illustrated in Fig. 2, the concentrations of PAHs decreased gradually with increasing the depth from the soil surface. The highest PAHs content was $4624.58 \mu \mathrm{g} / \mathrm{kg}$ in the surface soil of $0-10 \mathrm{~cm}$. Maliszewska-Kordybach [11] classified the soil contaminated by PAHs to four levels, which was shown in Table 1. The three classification thresholds were 200,600 and $1000 \mu \mathrm{g} / \mathrm{kg}$, obtained from the monitored concentrations in European soils and from an estimation of human exposure risks [12]. It can be seen from Fig. 2 and Table 1 that the soils from surface to the 40-50 cm depth were all classified as "Heavily contaminated", the soil layers of $50-60 \mathrm{~cm}$ and $60-70 \mathrm{~cm}$ were fallen under "Weakly contaminated" classification, and the soils from 70-80 cm to 90-100 cm depth were under the class "Not contaminated". Moreover, It can be noticed from Fig. 2 that the decrease rate of PAHs in the depth of 0-40 cm was slower than in the depth of 40-100 cm. In 0-40 cm soil layers, the light 
PAHs components were volatile and easily degraded, leading to no significant differences of PAHs concentrations among upper layers of the soil profile. In 40-100 cm soil layers, the organic matter content decreased and the clay content increased, resulting in the gradual decrease of PAHs in bottom layers of the soil profile.

Table 1 Classification of soil contamination by PAHs [11]

\begin{tabular}{cc}
\hline Class of soil contamination & PAHs $(\mu \mathrm{g} / \mathrm{kg} \mathrm{d} . \mathrm{w})$. \\
\hline Not contaminated & $<200$ \\
Weakly contaminated & $200-600$ \\
Contaminated & $600-1000$ \\
Heavily contaminated & $>1000$ \\
\hline
\end{tabular}

The highest concentration of $88.10 \mathrm{mg} / \mathrm{kg}$ for n-alkanes was found in 10-20 cm depth of the soil profile. The n-alkanes content in $0-10 \mathrm{~cm}$ soil layer was $83.35 \mathrm{mg} / \mathrm{kg}$, slightly lower than that in $10-20 \mathrm{~cm}$ soil layer. The concentration of n-alkanes was sharply decreased from $88.10 \mathrm{mg} / \mathrm{kg}$ in $10-20 \mathrm{~cm}$ soil layer to $30.08 \mathrm{mg} / \mathrm{kg}$ in $20-30 \mathrm{~cm}$ soil layer. Then the n-alkanes content gradually decreased with the increase depth below $30 \mathrm{~cm}$.

The vertical distribution of BTEX showed that the concentration increased gradually from the surface to the 30-40 cm depth and then decreased rapidly from 30-40 cm depth to $90-100 \mathrm{~cm}$ depth of the soil profile. The highest concentration of BTEX was $3293.68 \mu \mathrm{g} / \mathrm{kg}$ at $30-40$ depth of the soil profile. The BTEX components were easier to be dissolved in water than PAHs and n-alkanes, which led to that BETX components could move to underlying layers from the surface soil with rainfall infiltration and leaching. Consequently, the BETX content reached the peak at 30-40 cm depth of the soil profile. In the bottom layers, the increase of soil viscosity resulted in that BTEX was difficult to move to the next layers.

In addition, the vertical distribution of sulfur was similar to that of TPHs. The sulfur concentration decreased rapidly from $1298.50 \mathrm{mg} / \mathrm{kg}$ in the soil of $0-10 \mathrm{~cm}$ depth to $307.67 \mathrm{mg} / \mathrm{kg}$ in the soil of 20-30 cm depth. Then, the sulfur concentration increased slightly to $314.13 \mathrm{mg} / \mathrm{kg}$ at $30-40 \mathrm{~cm}$ soil layer. At last, the sulfur content decreased slowly from the $30-40 \mathrm{~cm}$ depth to $90-100 \mathrm{~cm}$ depth of the soil profile. The sulfur mostly exists in the asphaltene component of oil, which was hardly soluble in water, resulting in that the sulfur was difficult to migrate to the underlying layers.

\section{Summary}

The vertical distribution of typical petroleum pollutants in oil-polluted soil of Gudao Region were studied. The methods of GC, GC-MS and purge-and trap-GC were applied to analyze the petroleum pollutants. The results showed that the highest concentrations of the five petroleum pollutants were all found in the range of $0-40 \mathrm{~cm}$ soil layers. The concentrations of these pollutants decreased with increasing the soil depth from $40-50 \mathrm{~cm}$ to $90-100 \mathrm{~cm}$. The peak concentrations of TPHs, PAHs and sulfur were $33.84 \mathrm{~g} / \mathrm{kg}, 4624.58 \mu \mathrm{g} / \mathrm{kg}$ and $1298.50 \mathrm{mg} / \mathrm{kg}$, respectively, all apeared in the $0-10 \mathrm{~cm}$ soil layer of the profile. The highest content of n-alkanes was $88.10 \mathrm{mg} / \mathrm{kg}$, finding in the $10-20 \mathrm{~cm}$ depth of the soil profile. Additionally, for BETX, the content of $3293.68 \mu \mathrm{g} / \mathrm{kg}$ was highest, which was found at the $30-40 \mathrm{~cm}$ soil layer. The soil size and organic matter content affected the vertical distribution of the petroleum pollutants. In conclusion, the study results could provide important data for pollution monitoring and oil-polluted soil remediation.

\section{Acknowledgements}

The study was supported by ministry of environment production's special funds for scientific research on public causes No. 201109022 and the Scientific Research Funds for Yong Scholars of Weifang University of Science and Technology (No sdlgy2013w003). 


\section{References}

[1]. Hu Limin, Guo Zhigang, Feng Jialiang, et al. Distributions and sources of bulk organic matter and aliphatic hydrocarbons in surface sediments of the Bohai Sea, China. Marine Chemistry. Vol. 113 (2009) No. 3, p. 197-211.

[2]. Benlahcen K.T., Chaoui A., Budzinski H., et al. Distribution and sources of polycyclic aromatic hydrocarbons in some Mediterranean coastal sediments. Marine Pollution Bulletin. Vol. 34 (1997) No. 5, p. 298-305.

[3]. Chen Jianyao, Taniguchi Makoto, Liu Guanqun, et al. Nitrate pollution of groundwater in the Yellow River delta, China. Hydrogeology Journal. Vol. 15 (2007) No. 8, p. 1605-1614.

[4]. Song Jinming. Transferable phosphorus in sediments of the Huanghe River estuary's adjacent waters. Chinese Jounal of Oceanology and Limnology. Vol. 19 (2001) No. 1, p. 81-86.

[5]. Hui Yamei, Zheng Minghui, Liu Zhengtao, et al. Distribution of polycyclic aromatic hydrocarbons in sediments from Yellow River Estuary and Yangtze River Estuary, China. Journal of Environmental Sciences. Vol. 21 (2009) No. 12, p. 1625-1631.

[6]. Luo Xuemei, Liu Changming, He Mengchang. Distribution and origin of polycyclic aromatic hydrocarbons(PAHs) in sediment from the Yellow River. Research on Environmental Science (In Chinese). Vol. 18 (2005) No. 2, p. 48-50.

[7]. Feng Jinglan, Liu Menglin, Liu Shuhui, et al. Source Apportionment and Risk Assessment of Polycyclic Aromatic Hydrocarbons (PAHs) in Surface Sediments from Upper Reach of Huaihe River, China. Polycyclic Aromatic Compounds. Vol. 35 (2015) No. 5, p. 416-427.

[8]. Wang Chuanyuan, Wang Wanchun, He Shijie, et al. Sources and distribution of aliphatic and polycyclic aromatic hydrocarbons in Yellow River Delta Nature Reserve, China. Applied Geochemistry. Vol. 26 (2011) No.8, p. 1330-1336.

[9]. SEPAC. Environmental Quality Standard for Soils (In Chinese). Chinese environmental sciences press, Beijing, 1995.

[10]. Liu Wuxing, Luo Yongming, Teng Ying, et al. A survey of petroleum contamination in several Chinese oilfield soils. Soils (in Chinese). Vol. 39 (2007) No. 2, p. 247-251.

[11]. Maliszewska-Kordybach Barbara. Polycyclic aromatic hydrocarbons in agricultural soils in Poland: preliminary proposals for criteria to evaluate the level of soil contamination. Applied Geochemistry. Vol. 11 (1996) No. 1, p. 121-127.

[12]. Paterson Sally, Mackay Donald. A model illustrating the environmental fate, exposure and human uptake of persistent organic chemicals. Ecological Modelling. Vol. 47 (1989) No.1, p. 85-114. 